\title{
An integrated approach for structural damage identification using wavelet neuro-fuzzy model
}

\author{
Futao Zhu ${ }^{a}$, Zhongmin Deng ${ }^{\mathrm{a}, *}$, Junfeng Zhang ${ }^{\mathrm{b}}$ \\ a School of Astronautics, Beijing University of Aeronautics and Astronautics, 37 XueYuan Road, Haidian District, Beijing 100191, China \\ ${ }^{\mathrm{b}}$ Institute of Mechanics, Chinese Academy of Sciences, 100080 Beijing, China
}

\section{A R T I C L E I N F O}

\section{Keywords:}

Signal processing approach

Structural damage identification

Wavelet real-time filtering algorithm

Adaptive Neuro-Fuzzy Inference System

Interval modeling technique

\begin{abstract}
A B S T R A C T
Structural damage can be identified by processing structural vibration response signals and excitation data, and thus the suitability of signal processing methods is essential to structural damage identification. To explore an intelligent signal processing method for structural damage identification, the paper integrated wavelet real-time filtering algorithm, Adaptive Neruo-Fuzzy Inference System (ANFIS) and interval modeling technique to process structural response signals and excitation data. With Wavelet Transform (WT) algorithm filtering random noise, ANFIS was found to model the structural behavior properly and interval modeling technique to quantify damage index accurately. The rapid identifications of several unknown damages and small damages indicate the efficiency of this integrated method. The comparison of these results and some other signal processing methods shows that, the proposed method can be used to identify both the time and the location when the structural damage occurs unexpectedly. (c) 2013 Elsevier Ltd. All rights reserved.
\end{abstract}

\section{Introduction}

Vibration based damage identification approach is a common kind of structural damage identification method. In these methods, Wavelet Transformation (WT) method has been widely exploited in treatment of vibration response and construction of damage feature extractor; Adaptive Neuro-Fuzzy Inference System (ANFIS) has been used to indicate damage characteristic. In most studies, WT was used as an effective signal analysis tool and brings damage-incurred singularities into prominence, addressing features of damage and enabling a solution to damage identification (Cao, Cheng, $\mathrm{Su}, \& \mathrm{Xu}, 2012$ ). ANFIS can be fed into extracted features in order to identify the size and position of the damage and to estimate structural operating conditions (Saeed, Galybin, \& Popov, 2013).

One of the difficulties in identification process is the treatment of uncertainty caused by noise and variability, which has been well handled by WT algorithm (Peretto, Sasdelli, \& Tinarelli, 2005), ANFIS (Ch \& Mathur, 2010) or interval modeling technique (Lew, 2011). WT algorithm and ANFIS may be integrated by interval modeling technique.

The uncertainty of vibration response in helicopter is caused by numerous complex loading conditions, highly flexible uses and strong randomicity in maneuvering, etc. Flap, lag, and torsion motions of rotor system in the non-symmetric flow caused by rotating

\footnotetext{
* Corresponding author. Tel.: +86 01082339526.

E-mail addresses: zhufutao1990cool@163.com (F. Zhu), dengzhongmin@buaa. edu.cn (Z. Deng), zhangj@@imech.ac.cn (J. Zhang).
}

and sliding lead to complicated aerodynamic coupling load and structural vibration load acting on moving parts and adjacent structures. Furthermore, vibration phenomenon is the intrinsic characteristic of helicopter, which causes $40 \%$ of the accidents. Thus, helicopter structural damage identification using vibration response is challenging yet plausible if the uncertainty is carefully processed.

The main task of this paper is to deal with uncertainty using signal processing algorithm in the process of helicopter structural damage identification, and the purpose is to explore an intelligent approach for vibration based structural damage identification using wavelet real-time filtering algorithm, ANFIS and interval modeling technique cooperatively. The integrated approach takes WT method as a real-time filtering algorithm, ANFIS as a structural response behavior modeling tool, and interval modeling technique as a damage feature extractor.

The proposed approach begins by filtering the sensor's output time series with wavelet real-time filtering algorithm. After trained by input-output time series, ANFIS is then used to model the structure and predict the displacement response. The interval modeling technique accepts prediction results as the input and gives uncertainty coordinates as the output. Information fusion is subsequently accomplished and then the damage can be identified after damage index is constructed.

This approach can be used as a structural damage identification method, which provides new ideas for structural modeling and structural damage feature extracting. Furthermore, this study may cast light on parameter identification schemes. 


\section{Background information}

Structural damage identification (SDI) has received much attention in the field of aerospace engineering. Numerous techniques have been introduced for the damage detection of aircraft structures, among which the vibration based approaches have been widely exploited (Bayissa, Haritos, \& Thelandersson, 2008; Budipriyanto, Haddara, \& Swamidas, 2007; Duffey, Doebling, Farrar, Baker, \& Rhee, 2001). These methods are based on the fact that any structure can be interpreted as a dynamic system with stiffness, mass and damping. Once some damages occur in the structure, the structural parameters will change, and the modal parameters of the structural system and timehistory response will also shift. Thus, the change of the structural modal parameters or any other features extracted from the vibration responses through signal processing methods can be taken as the indications of early damage occurrence in the structural system.

A difficulty in the procedure of damage monitoring, localization and status identification is handling various uncertainties (Li \& Law, 2008; Zhang, Li, Duan, \& Law, 2011). For vibration response based structural damage identification methods, transmissibility measurements are always subject to environmental, operational and measurement variability, and the uncertainty will propagate through to any features derived from it, leading to misinterpretation and false alarms (Mao \& Todd, 2012). Uncertainty caused by noise and variability has successfully been quantified with signal processing methods such as WT algorithm (Tay, 2004; Wu \& Deng, 2008), ANFIS (Noori, Hoshyaripour, Ashrafi, \& Araabi, 2010; Theodoridis, Boutalis, \& Christodoulou, 2010) and interval modeling technique (Lew \& Loh, 2012; Red-Horse \& Paez, 2008). Furthermore, the incorporation of the three methods generates a better effect on identifying structural damage.

For signal processing methods dealing with system uncertainty, WT, ANFIS and interval modeling technique play different roles in structural damage identification. When time series is estimated and predicted, modeling uncertainties are smaller if processed by ANFIS than by ANN (Talebizadeh \& Moridnejad, 2011). However, ANFIS may not be able to cope with non-stationary data, if preprocessing of the input and/or output data is not performed (Noori, Abdoli, Farokhnia, \& Abbasi, 2009), which can be effectively addressed by using WT algorithm (Manimaran, Panigrahi, \& Parikh, 2009; Noori et al., 2009). Furthermore, WT algorithm can substantially improve structural modeling capacity of ANFIS (Altmann \& Mathew, 2001; Catalao, Pousinho, \& Mendes, 2011; Najah, El-Shafie, Karim, \& Jaafar, 2012). Fitting of structural vibration response can be realized by wavelet-based ANFIS method (Mitchell, Kim, \& El-Korchi, 2012), which as a single output system (Chen, Zhang, \& Ieee, 2005; Melin, Soto, Castillo, \& Soria, 2012) yet cannot directly identify damage of multi-sensor structures. This issue can be supplemented by introducing interval modeling technique (Lew \& Horta, 2007; Red-Horse \& Paez, 2008) through information fusion (Rodger, 2012).

Interval modeling technique, a kind of parameter uncertainty quantitative method suitable for sampling control system, has been used for aircraft real-time structural damage identification (Lew \& Loh, 2012). The application of ANFIS or WT algorithm as system feature extractor to structural damage detection and localization under different excitations has been widely researched (Escamilla-Ambrosio, Lieven, \& Ieee, 2007; Gketsis, Zervakis, \& Stavrakakis, 2009; Nair \& Kiremidjian, 2009; Noh, Lignos, Nair, \& Kiremidjian, 2012). But to the author's knowledge, the previous studies have not involved interval modeling technique as damage feature extractor or ANFIS as structural modeling tool in structural damage identification, and there is little information available in literature about an integrated method assigning different roles according to the specialties of its signal processing subsystems for vibration response based structural damage identification.

This paper proposes an integrated signal processing approach for vibration based structural damage identification using interval modeling technique for wavelet filtered neuro-fuzzy system. This method is demonstrated by application to an unmanned helicopter model and the results show that the integrated approach can greatly improve damage identification capacity. The next section describes the basics of wavelet-based ANFIS modeling and vibration response prediction.

\section{Structural system modeling and vibration response prediction}

For vibration based structural damage identification methods, displacement response is often employed for deciding structural damage state. The displacement response of the structure under periodic excitation appears the same period and proportional vibration amplitude as the excitation, when there is no noise. The actual condition may be described as Fig. 1.

For suddenly occurred structural damage, there is an oscillation progress initiating from damage occurring and continuing to the moment when abnormal displacement amplitude reaches steady state. This transient time depends on structural damage scale and magnitude of load. Uncertainty in displacement response can be estimated and quantified using wavelet based ANFIS and interval modeling technique. Structural damage can also be treated as a kind of uncertainty, which is steady for undamaged structure, but is an abnormal value for damaged structure in oscillation state. Damage feature can subsequently be extracted through processing of displacement response.

\subsection{Wavelet-based ANFIS modeling}

ANFIS is an effective tool for structural system modeling and time series prediction, whose capacity can be elevated by using WT algorithm (Samant \& Adeli, 2001), and this promoted method has been successfully used in smart structure modeling (Mitchell et al., 2012). Wavelet-based ANFIS is called WT-ANFIS (Noori et al., 2009) or WANFIS (Guo, Dong, \& Ma, 2009).

First proposed by Jang (1993), ANFIS is formed by combining the adaptive learning capability of neural networks with imprecision modeling capability of fuzzy logic (Samant \& Adeli, 2001). Neural network is suitable for processing unstructured information, while fuzzy system is fit for dealing with structured knowledge. Fuzzy logic and neural network achieve the non-parameter modeling of nonlinear system by training data to input-output map of the system (Mitchell et al., 2012).

There are two kinds of structures using neural network to realize fuzzy system: fuzzy neural networks based on the Mamdani model and on Takagi-Sugeno model (Takagi \& Sugeno, 1985). ANFIS, adopting the latter, refers to fuzzy inference system based on adaptive networks (Melin et al., 2012). ANFIS performs better than single neural network or single fuzzy system (Das, Maiti, \& Banerjee, 2010).

While ANFIS is an effective modeling tool, the adopted input/ output vibration response are usually noisy and the subsequent feature extraction of signal components is quite difficult (Jafarizadeh, Hassannejad, Ettefagh, \& Chitsaz, 2008). One of the solutions to this problem is applying wavelet filtering algorithm in time domain for signal denoising (Arzhantsev, Li, \& Kauffman, 2011).

The essence of wavelet filtering is to process the WT coefficient non-linearly, and then to reconstruct it (Han, Wang, Shang, \& An, 2009). For wavelet transformation, useful signal energy is 


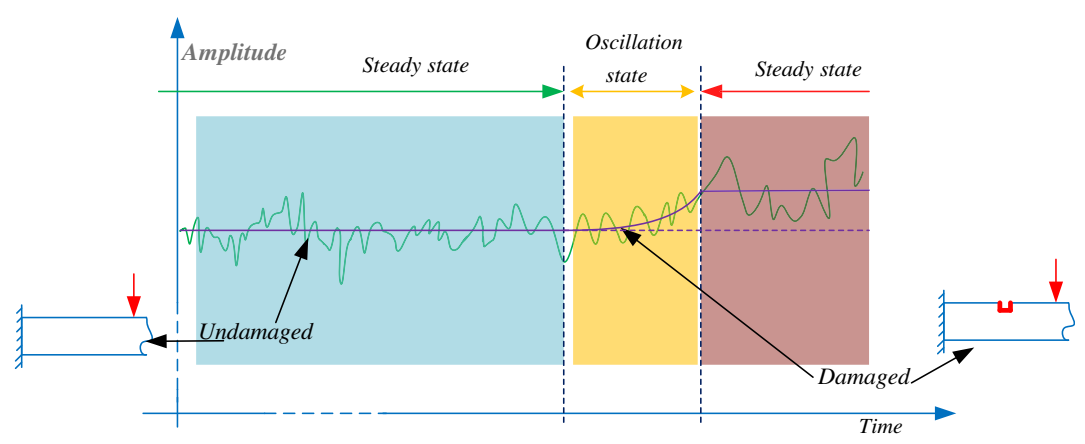

Fig. 1. Relationship between amplitude of vibration response and time depending on damage state.

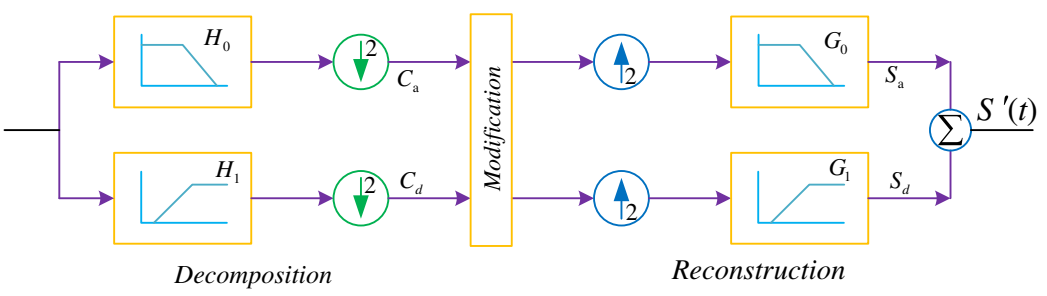

Fig. 2. Wavelet transform and filtering.

centralized in a few wavelet coefficients with larger absolute value, whilst noise signal energy is scattered with smaller absolute value. After resetting the wavelet coefficient below the threshold value, filtered signal can be reproduced by reconstructing it. Fig. 2 (Mohammed, Khan, El-Tallawy, Nejadpak, \& Roberts, 2012) depicts the steps of real-time filtering algorithm:

ANFIS modeling for structure:

A structural parameter identification approach using displacement measurement time series has been proposed (Xu, Song, \& Masri, 2012). The dynamic displacement response of the frame structure under the measured excitation can be used to train the neural network to map the function from displacement vector $x_{k-1}, x_{k-2}$ and excitation vector $\ddot{x}_{g, k-1}$ to $x_{k}$ of the structure. After being trained, the neural network can be employed to forecast $x_{k}$ according to $x_{k-1}, x_{k-2}$ and $\ddot{x}_{g, k-1}$ :

$x_{k}^{f}=f_{\text {ANN }}\left(x_{k-2}, x_{k-1}, \ddot{x}_{g, k-1}\right) \quad(k=2, \ldots, K)$

where $x_{k}^{f}$ is the forecasted displacement response of the structure at time $k T$.

The above formula, predicting dynamic displacement response of the observed structure, can also be presented as the following expression:

$X(k+1)=G(x(k), x(k-1), f(k)) \quad(k=2, \ldots, k)$

When time series is estimated and predicted, modeling uncertainties are smaller if processed by ANFIS than by ANN (Talebizadeh \& Moridnejad, 2011). And ANFIS has been used to obtain the input (the location and depth of a crack)-output (the structural Eigen frequencies) relation of the structural system (Shim \& Suh, 2002). In this paper, ANFIS is used to simulate the above formula in order to accomplish the structural modeling, and to finally achieve

$\hat{x}(k)=f_{\text {ANFIS }}(x(k-1), x(k-2), f(k-1)) \quad(k=3, \cdots, K)$

The function of the above formula is to predict displacement vector $x(k)$ at time $k$ from displacement vector $x(k-1)$ at time $k-1$, displacement vector $x(k-2)$ at time $k-2$, and excitation vector $f(k-1)$ at time $k-1$. The above formula is the realization of structural modeling and vibration response prediction.

\subsection{Vibration response prediction}

\subsubsection{Response prediction of structure under sinusoidal excitation}

The fuselage structure of BUAA FH-1 coaxial unmanned helicopter is used for example analysis, whose size and shape are shown in Fig. 3 (Xufei, Zhongmin, \& Zhitao, 2012). Young's modulus, density and Poisson's ratio of the fuselage material are $207 \mathrm{GPa}, 7780 \mathrm{~kg} /$ $\mathrm{m}^{3}$ and 0.3 , respectively. Rayleigh damping model is employed to depict the structural damping of the fuselage, whose $\alpha$ and $\beta$ are 3 and 0.0001 separately. Six degrees of freedom constraint are added to the joint of the fuselage and the landing gear. $f_{1}$ and $f_{2}$ are the same in Fig. 3, and are used to simulate the cycle loading the blade acts on the fuselage, which is $100 \sin (80 \pi t)+100 \cos$ $(160 \pi t) N$. The displacements are output in the tagged 14 points, which are shown in Table 1. Fig. 4 shows the structural dynamic response under $10 \%$ measurement noise level. Fig. 5 depicts the excitation signal with $10 \%$ noise.

This paper studies 4 positions and 16 types of damage. Positions of damage occurring in the four diagonal braces are respectively S1, S2, S3 and S4. 16 types of damage, representing degree of

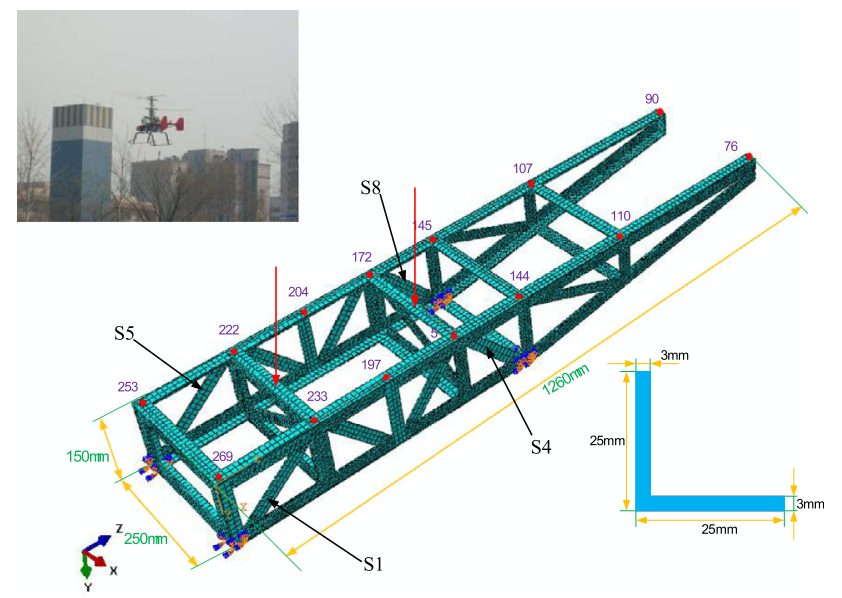

Fig. 3. Finite element model of FH-1 unmanned helicopter fuselage structure. 
Table 1

Mapping from node number to displacement output number.

\begin{tabular}{|c|c|c|c|c|c|c|c|c|c|c|c|c|c|c|}
\hline Node number & 90 & 107 & 145 & 172 & 204 & 222 & 253 & 76 & 110 & 144 & 5 & 197 & 233 & 269 \\
\hline Output number & 1 & 2 & 3 & 4 & 5 & 6 & 7 & 8 & 9 & 10 & 11 & 12 & 13 & 14 \\
\hline
\end{tabular}

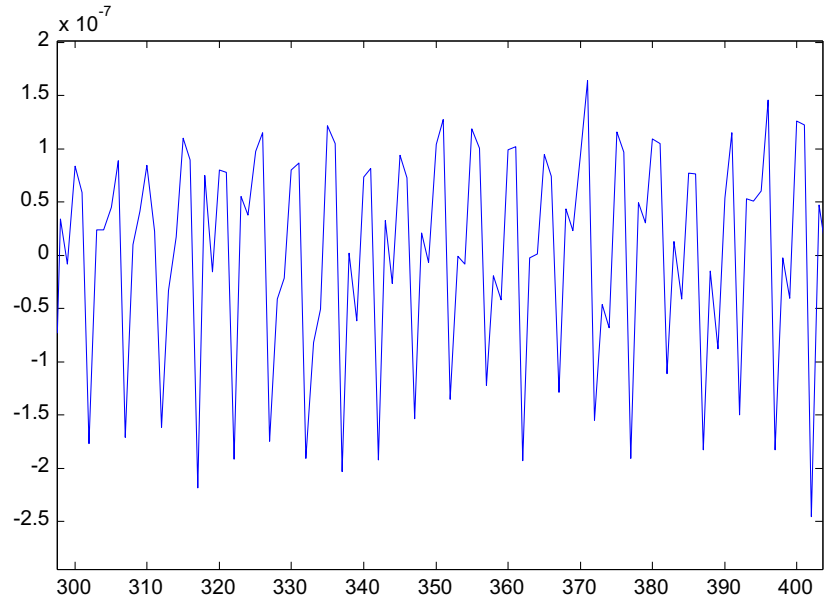

Fig. 4. Vibration response with $10 \%$ noise.

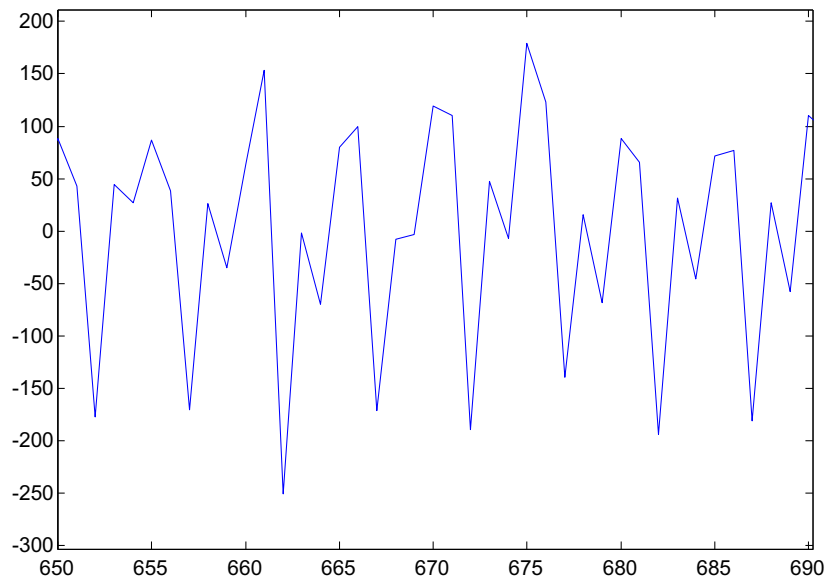

Fig. 5. Excitation signal with $10 \%$ noise.

damage, are respectively S1-2e5, S1-15, S1-50, S1-100, S4-4, S4-12, S4-50, S4-100, S5-3, S5-12, S5-50, S5-100, S8-3, S8-12, S8-50 and S8-100. Damages S1-2e5 and S4-100 are depicted in Figs. 6 and 7. Fig. 8 depicts the initial membership functions (MFs) for each input variable and illustrates the MFs after learning. Three kinds of MFs, namely gaussmf, gbellmf and gauss $2 \mathrm{mf}$, are used as input MF type, and linear MF is used as output MF type. See Table 2.

Typical adaptive network representation of fuzzy reasoning is shown in Fig. 9. In this simulation example, grid partition method is used to generate ANFIS, and the number of membership functions for $x(k-1), x(k-2)$ and $f(k-1)$ is all set to be 3. Fuzzy logic package of MATLAB R2011b is used for implementation of ANFIS. Computing platform uses Windows XP Pack 3 as the operating system and the computer uses Pentium Dual-Core $2.5 \mathrm{GHz}$ CPU with 2G RAM. The ANFIS structure is depicted in Fig. 10(a), and membership functions of $x(k-1)$ are shown in Fig. 10(b). The number of fuzzy if-then rules in the rule base is $3 \times 3 \times 3=27$. The rule base is shown in Fig. 10(c) and 7 rules of it are listed as follows:

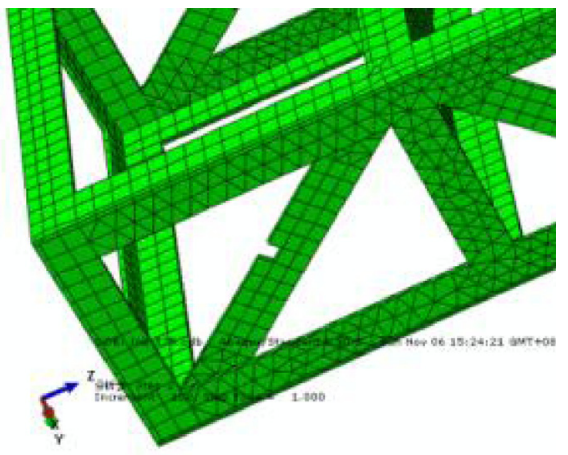

Fig. 6. Model of damage type S1-2e5.

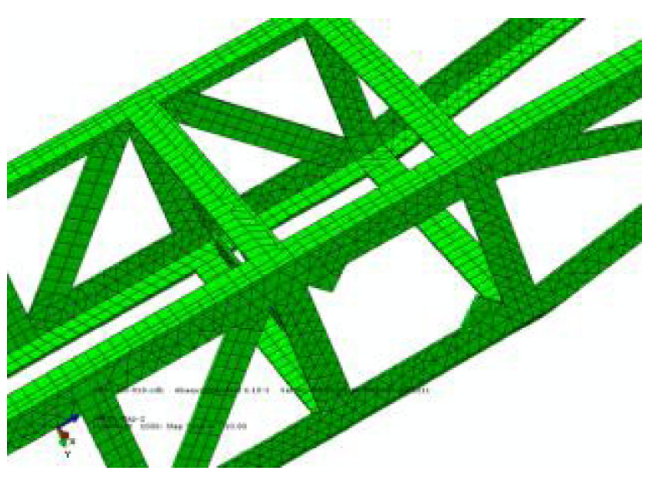

Fig. 7. Model of damage type S4-100.

Rule 1: If (input1 is in $1 \mathrm{mf} 1$ ) and (input2 is in $2 \mathrm{mf} 1$ ) and (input3 is in $3 \mathrm{mf} 1$ ) then (output is out $1 \mathrm{mf} 1$ )

Rule 2: If (input1 is in $1 \mathrm{mf} 1$ ) and (input2 is in $2 \mathrm{mf} 1$ ) and (input3 is in $3 \mathrm{mf} 2$ ) then (output is out1 mf2)

Rule 3: If (input1 is in $1 \mathrm{mf} 1$ ) and (input2 is in $2 \mathrm{mf} 1$ ) and (input3 is in $3 \mathrm{mf} 3$ ) then (output is out $1 \mathrm{mf} 3$ )

Rule 4: If (input1 is in $1 \mathrm{mf} 1$ ) and (input2 is in $2 \mathrm{mf} 2$ ) and (input3 is in $3 \mathrm{mf} 1$ ) then (output is out $1 \mathrm{mf} 4$ )

Rule 7: If (input1 is in $1 \mathrm{mf} 1$ ) and (input2 is in $2 \mathrm{mf} 3$ ) and (input3 is in3mf1) then (output is out1mf7)

Rule 10: If (input1 is in $1 \mathrm{mf} 2$ ) and (input2 is in $2 \mathrm{mf} 1$ ) and (input3 is in $3 \mathrm{mf} 1$ ) then (output is out $1 \mathrm{mf} 10$ )

Rule 19: If (input1 is in $1 \mathrm{mf} 3$ ) and (input2 is in $2 \mathrm{mf} 1$ ) and (input3 is in3mf1) then (output is out1mf19)

\section{Integrated approach using interval modeling technique}

To cope with the single-output property of wavelet-based ANFIS and construct an ensemble ANFIS model, several methods (Chen \& Zhang, 2005; Melin et al., 2012) have been proposed, including average method and weighted average method. However, these two methods are just adjustments of outputs to reach a comprehensive result, and they can't act as structural damage feature extractors for identification usage. The principal component analysis (PCA) has been applied to extract features and reduce the dimensionality of the obtained Frequency Response Function (FRF) data (Saeed et al., 2013). Similar to PCA analysis, interval 


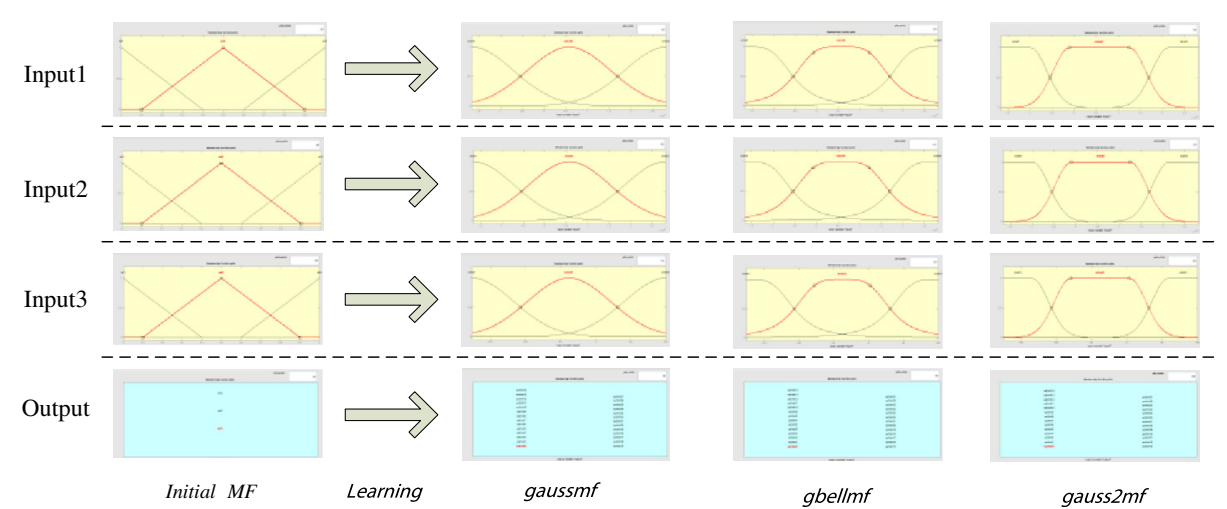

Fig. 8. MFs before and after learning.

Table 2

Information of ANFIS used to predict response at output node 1 without noise:

\begin{tabular}{ll} 
Number of nodes & 78 \\
Number of linear parameters & 108 \\
Number of nonlinear parameters & 18 \\
Total number of parameters & 126 \\
Number of training data pairs & 898 \\
Number of checking data pairs & 0 \\
Number of fuzzy rules & 27 \\
Error after 1 training epoch & $2.91792 \mathrm{e}-12$ \\
Training time & $2 \mathrm{~s}$ \\
\hline
\end{tabular}

modeling technique is used in this paper as structural damage feature extractor.

Fig. 11 depicts the integration of wavelet transform, ANFIS and interval modeling technique.

\subsection{Interval modeling technique and uncertainty quantification}

Interval modeling technique (Red-Horse \& Paez, 2008) was proposed to solve structural certification problem under various uncertainty conditions, and has been used to quantify uncertainty in multiple models resulting from tests and identifications (Lew \& Loh, 2012). In this paper, interval modeling technique is used for handling the output of multiple ANFIS systems and extracting damage feature to construct an ensemble ANFIS model.

In structural damage identification configuration, multiple sensors are used to collect the information of structural vibration response data. Data after real-time wavelet filtering and after ANFIS prediction are the feature data reflecting the characteristics of structural health status. Interval modeling technique is used to analyze and synthesize feature data, thus various uncertainties in feature data are transformed to dominant uncertainty coordinates, and consistency interpretation and health condition description of measured structure are finally achieved. SVD decomposition is used in interval modeling technique for uncertainty quantification (Lew \& Loh, 2012).

In this paper, the output of ANFIS is the predicted vibration response. For the results of $n$ tests, the definition of $\Delta p$ are as follows:

$\Delta p_{j}=p_{j}-p_{0}, \quad j=1, \ldots, n, \quad p_{0}=\frac{1}{n} \sum_{j=1}^{n} p_{j}$

where $p_{j}$ is the subtraction between response vector $x(j)$ and predicted response vector $\hat{x}(j)$, and $p_{0}$ is the nominal vector, which is computed as the average of all the $n$ vectors $p_{j}$.

(1) Calculate the basis matrix $U$

$\Delta P=U S V^{T}, \quad S=\operatorname{diag}\left[S_{1} \cdots S_{k}\right], \quad U=\left[q_{1} \cdots q_{k}\right]$
The singular values $s_{j}$ are in descending order, which leads to the descending order of perturbation distribution in $q_{j}$.

(1) Compute the coordinate vector corresponding to the basis vectors $q_{j}$

$\alpha\left(t_{i}\right)=U^{-1} \Delta p_{i}$

(1) Represent each parameter vector as

$p\left(t_{i}\right)=p_{0}+\sum_{j=1}^{k} \alpha_{j}\left(t_{i}\right) q_{j}$

where $\alpha_{j}\left(t_{i}\right)$ is the $j$ th element of the uncertainty coordinate vector $\alpha\left(t_{i}\right) . \alpha_{j}$ is the uncertainty coordinate corresponding to the $j$ th test. $n$ is the number of intervals used for SVD technique. $k$ is the number of elements both in response vector of each test and in uncertainty vector after decomposition. For the ensemble model, it is also the number of wavelet-based ANFIS systems.

The uncertainty in $k$ element displacement vectors is decomposed into uncertainty coordinate vectors of $k$ elements. The first uncertainty coordinate is much bigger than other $k-1$ uncertainty coordinates (Lew \& Horta, 2007), and it is called the dominant uncertainty coordinate. Thus, various uncertainties of multiple ANFIS systems resulting from multiple sensors are represented by the dominant uncertainty coordinates, and subsequently comprehensive interpretation results of the ensemble model and multi-sensor information fusion are accomplished.

\subsection{Integrated method for structural damage identification}

Damage index $M$ is settled through real-time processing of the dominant uncertainty coordinates. The occurrence of abnormal damage index value indicates damage occurrence. The flow chart of damage identification is shown in Fig. 12, and it also depicts the sequence of damage detection.

The uncertainty coordinates of 11 tests gained from uncertainty decomposition are

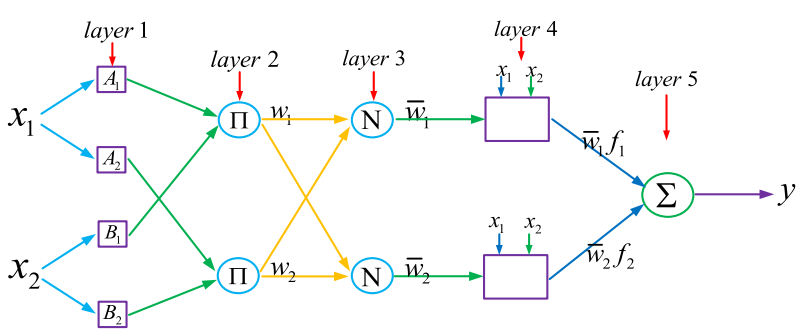

Fig. 9. Adaptive network representation of fuzzy reasoning (Jang \& Sun, 1993). 


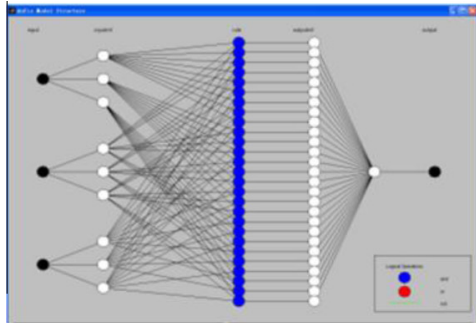

(a)

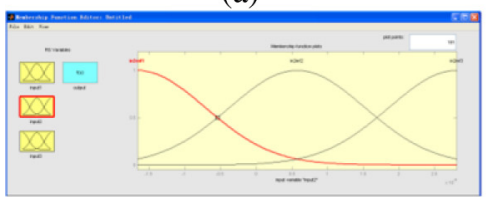

(b)
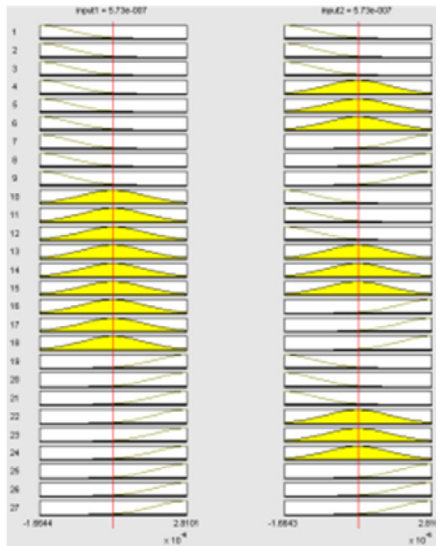

(c)

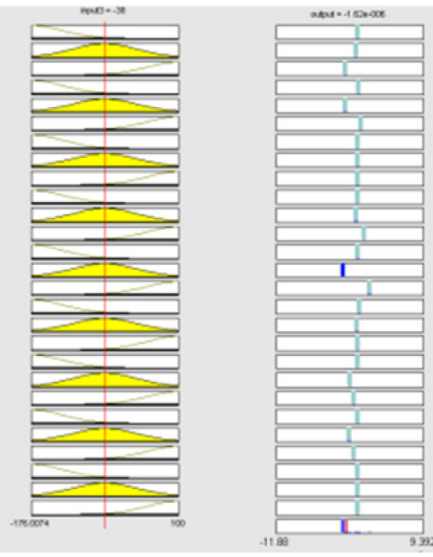

Fig. 10. (a): Structure of ANFIS; (b): membership function; (c): rule base of ANFIS.

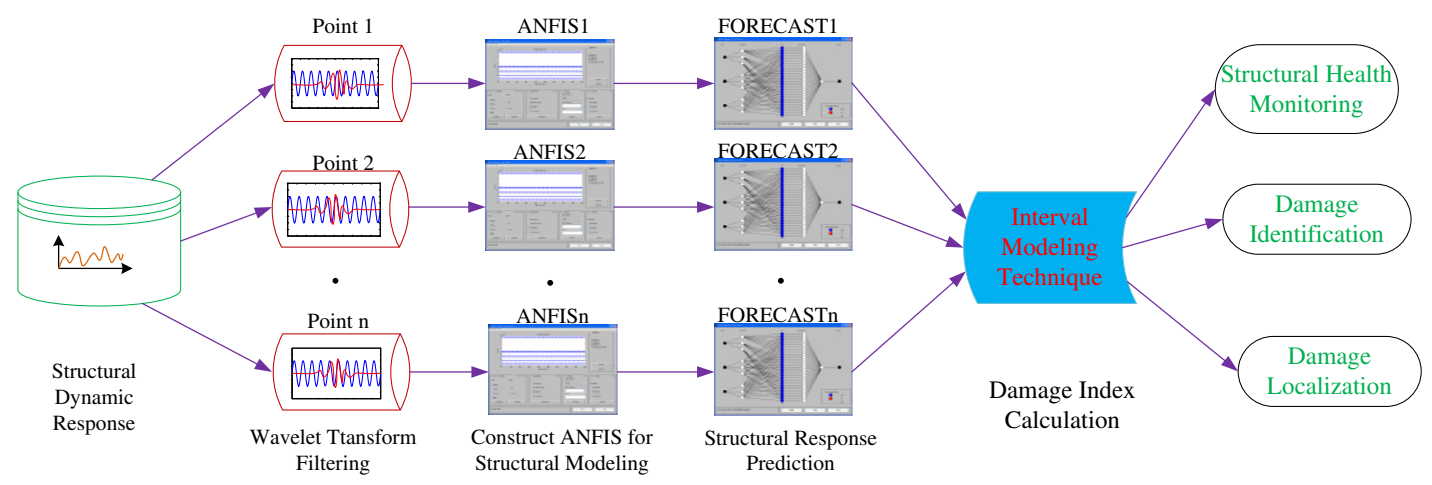

Fig. 11. Schematic diagram of integrated scheme using interval modeling technique.

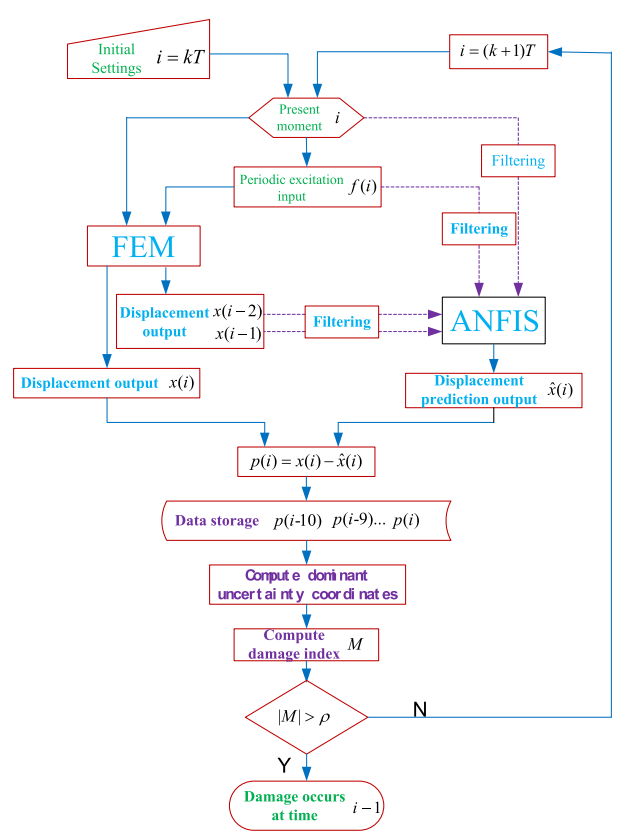

Fig. 12. Flow chart of structural damage identification.

$\alpha_{1}=\left[\alpha_{1}\left(t_{1}\right), \alpha_{1}\left(t_{2}\right), \ldots, \alpha_{1}\left(t_{11}\right)\right]$

The former 10 coordinates of uncertainty vectors are fit with a constant:
$R=\sum_{i=1}^{10}\left[b-\alpha_{1}\left(t_{i}\right)\right]^{2}$

where $\alpha_{1}\left(t_{i}\right)$ is the uncertainty coordinate at time $i . b$ is the constant used for fitting. Then the 11 uncertainty coordinates can be directly estimated as

$\hat{\alpha}_{1}\left(t_{i}\right)=b(i=1,2, \ldots, 10,11)$

Since there is no damage in the first 10 tests, their uncertainty coordinates are considered stable and controllable. The structure in the last test is "suspected" with damage, and an exception may happen to its uncertainty coordinates. The disturbance of uncertainty coordinates can be defined using

$\beta\left(t_{i}\right)=\alpha_{1}\left(t_{i}\right)-b(i=1,2, \ldots, 10,11)$

The last uncertainty coordinate is compared with the first 10 , and then its abnormalities are gained. The standard deviation $\sigma$ of the disturbance of the former 10 uncertainty coordinates is computed to measure the abnormalities, which is defined as damage index:

$M=\beta\left(t_{11}\right) / \sigma$

The above $M$ is computed at time $(i+1) T$ to identify the damage at time $i T$. If damage occurs at time $i T$, the above computed $M$ is defined as $M$ at time $i T$, symbolized by $M_{i T}$. Damage threshold is defined as

$\rho=\alpha \cdot \max \left(M_{i T}\right)$

where $\alpha$ is safety factor. If

$\left|M_{i T}\right|>\rho$ 
Then $M_{i T}$ is the identified abnormal value, which indicates damage at time $i T$ is identified at time $(i+1) T$.

Suppose damage time is $i T$ and identification time is $(i+1) T$. Then, displacement difference vector at time $(i+1) T$ can be expressed as

$p_{(i+1) T}=x((i+1) T)-\widehat{x}((i+1) T)$

To identify damage location, define $50 \%$ damage as "base damage" $S_{d}$, and displacement difference vector as "base vector". Then calculate the "base vector" $p_{j}^{S_{d}}$ of the $j$ th location damage by:

$R=\sum_{i=1}^{l}\left[p_{j}^{S_{d}}(i)-p_{j(i+1) T}^{S_{d}}(i)\right]^{2}$

where $l$ is the number of displacement sampling points on structure.

Fit $p_{j(i+1) T}^{S_{d}}$ of all "base damage" using 5 order polynomial, and get $p_{1}^{S_{d}}, J=1,2,3,4$.

The "base vectors" P1-50, P4-50, P5-50, P8-50 are:

$$
\mathrm{P} 1-50=p_{1}^{S_{d}} \quad \mathrm{P} 4-50=p_{2}^{S_{d}} \quad \mathrm{P} 5-50=p_{3}^{S_{d}} \quad \mathrm{P} 8-50=p_{4}^{S_{d}}
$$

Suppose the damage at $x \%$ degree is $S_{x}$, and there is damage at each location with $S$ kinds of degree. There are $J$ kinds of location and $R \times S$ types of damage in total. The displacement difference vector corresponding to $k$ th type of damage is $p_{(i+1) T}^{k}$. And subsequently damage location can be determined by computing "location factor"

$S P_{k}^{j}((i+1) T)=\frac{\left(p_{j}^{S_{d}}\right)^{T}\left(p_{(i+1) T}^{k}\right)}{\left\|p_{1}^{S_{d}}\right\|_{2} \cdot\left\|p_{(i+1) T}^{k}\right\|_{2}}$

where $\left\|p_{j}^{S_{d}}\right\|_{2}$ and $\left\|p_{(i+1) T}^{k}\right\|_{2}$ are Euclidean lengths of vectors $p_{j}^{S_{d}}$ and $p_{(i+1) T}^{k}$, respectively. The above $S P_{k}^{j}$ is between -1 and 1 . If the "location factor" approaches to 1 , then the damage to be determined is in the same position as the corresponding "base damage" $S_{d}$.

\section{Damage identification simulation results}

A common proposal of structural damage identification is to analyze structural vibration response induced by certain kinds of damage, and to check if the proposed method can identify the predefined damage. The damage type is known to the researcher and the studies examine the difference between healthy structure and damaged structure.

In this paper, 16 kinds of suddenly-occurred damage are predefined, which are simulated to occur at time $10 \mathrm{~s}$. Three unknown kinds of suddenly-occurred damage (among the 16 kinds of damage) are investigated. The results indicate that, the proposed method can identify the time and location of an unknown kind of damage at $0.01 \mathrm{~s}$ after its occurrence, which is shown in Section 5.1.

The proposed method is based on harmonic vibration response, which facilitates fast (at $0.01 \mathrm{~s}$ after damage's occurrence) and high precision identification. The comparisons with other methods using different excitations are depicted in Section 5.2.

Larger damage is identified more easily. This common sense is verified in Table 7 of Section 5.3. Figs. 17-22 in Section 5.3 depict identification results using membership function gaussmf, and in contrast, Table 7 depicts identification results using membership function gauss $2 \mathrm{mf}$. Section 5.4 discusses the possible limitations of the proposed method when it is applied to practical helicopter engineering.

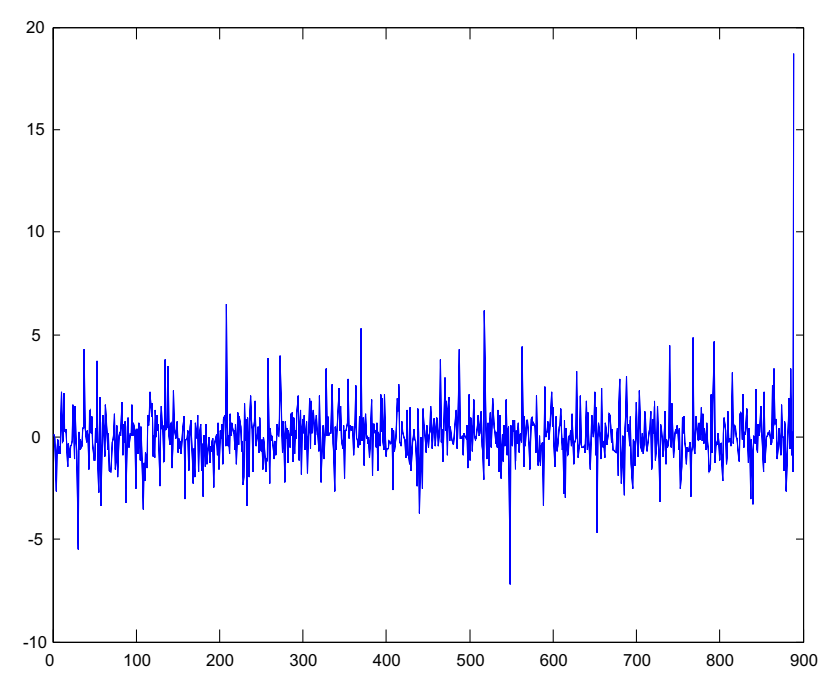

Fig. 13. Damage index variation of unknown damage 1 .

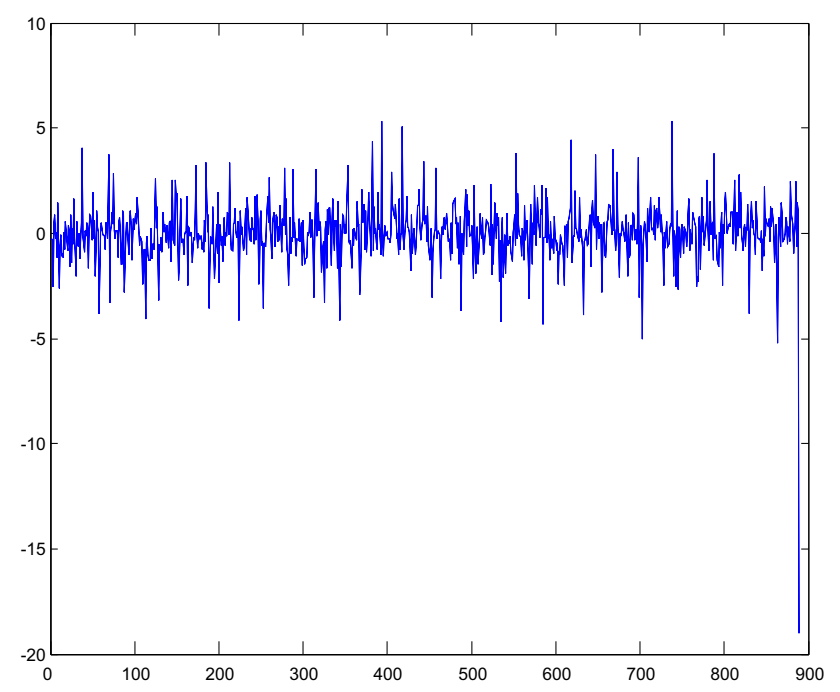

Fig. 14. Damage index variation of unknown damage 2 .

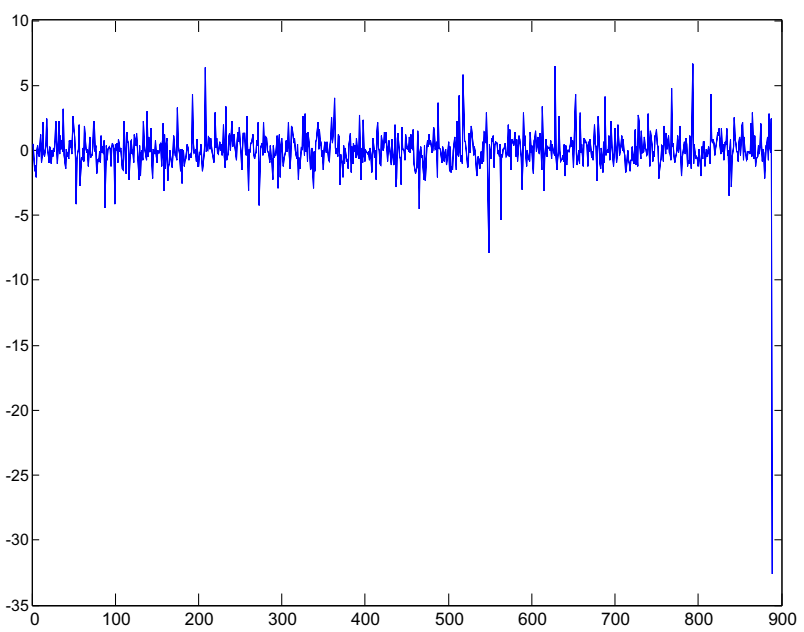

Fig. 15. Damage index variation of unknown damage 3. 

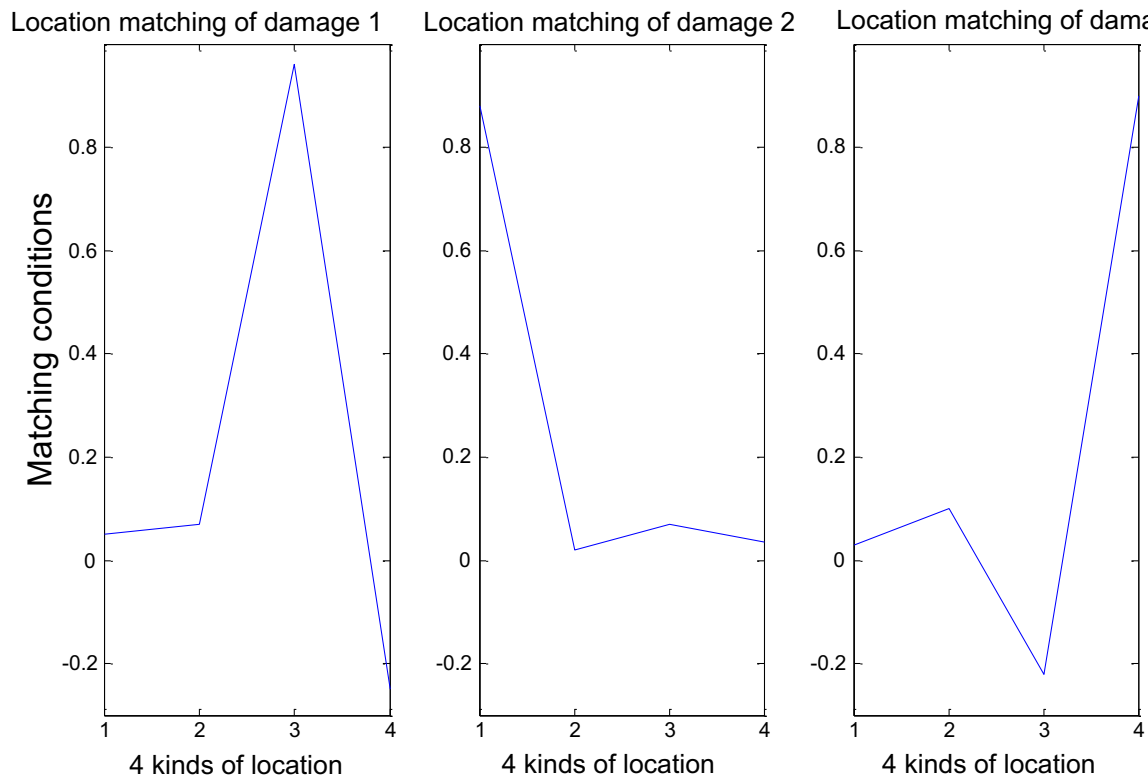

Fig. 16. Identification of unknown damage location.

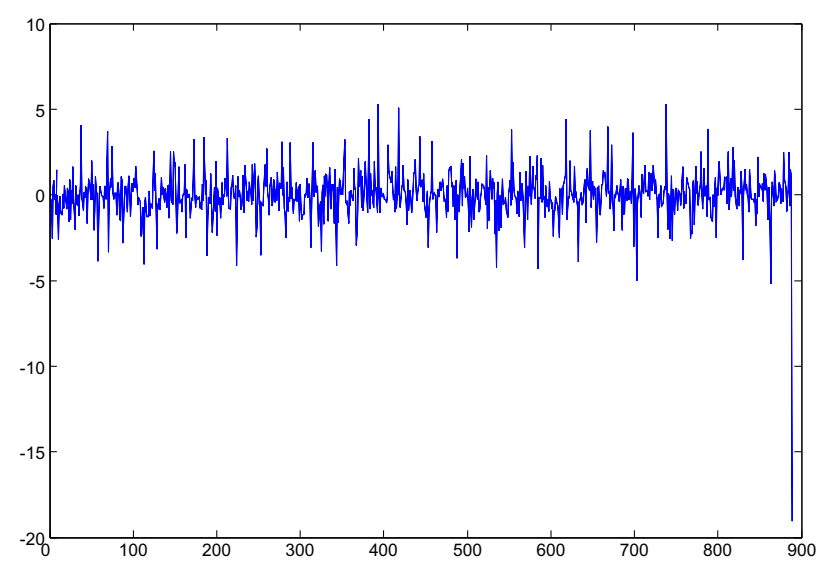

(a) gaussmf-5\%-S1-50

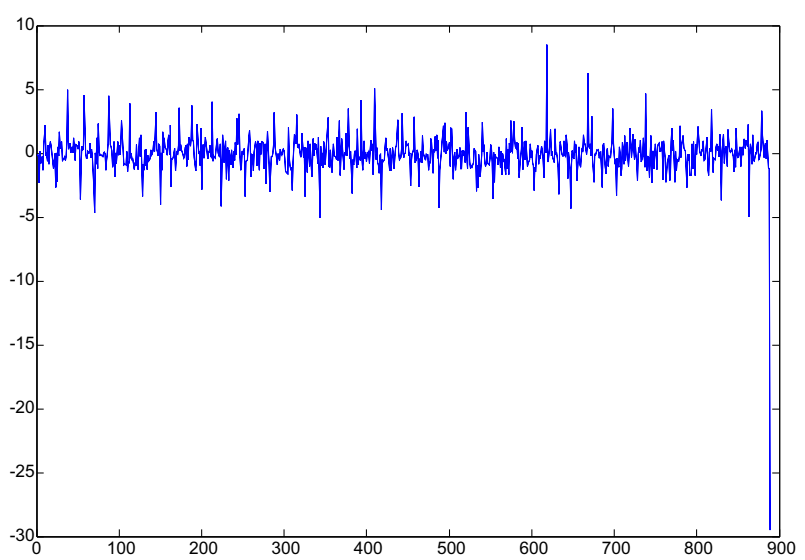

(b) gaussmf-5\%-S4-4

Fig. 17. Damage index variation for damage type $S 1-50$ (a) and damage type $S 4-4$ (b) using MF gaussmf under 5\% noise level.

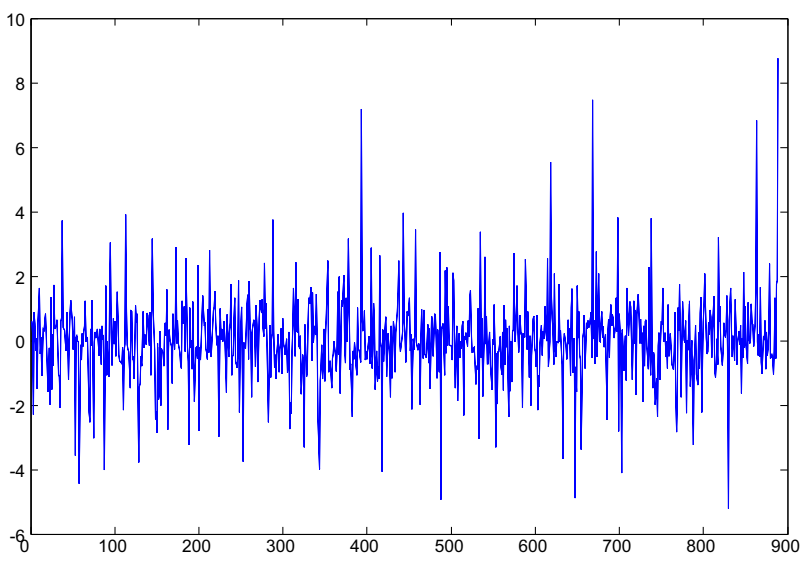

(a) gaussmf-5\%-S5-12

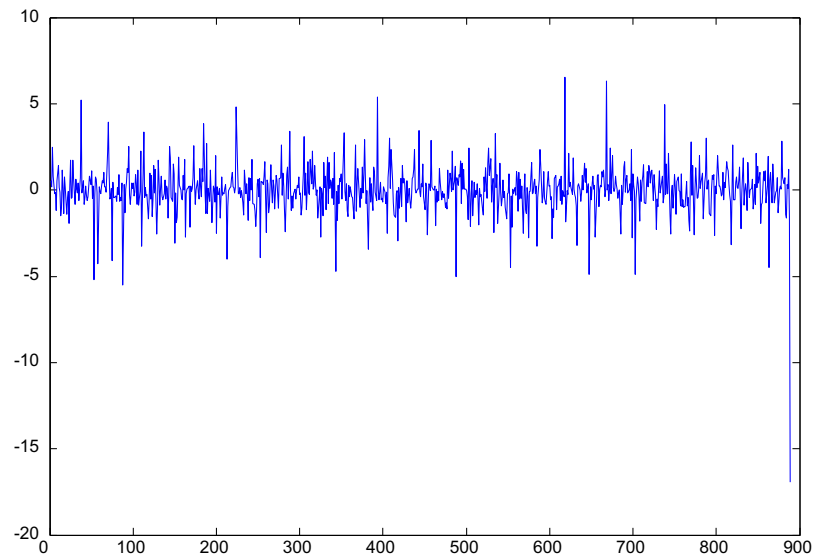

(b) gaussmf-5\%-S8-50

Fig. 18. Damage index variation for damage type S5-12 (a) and damage type S8-50 (b) using MF gaussmf under 5\% noise level. 


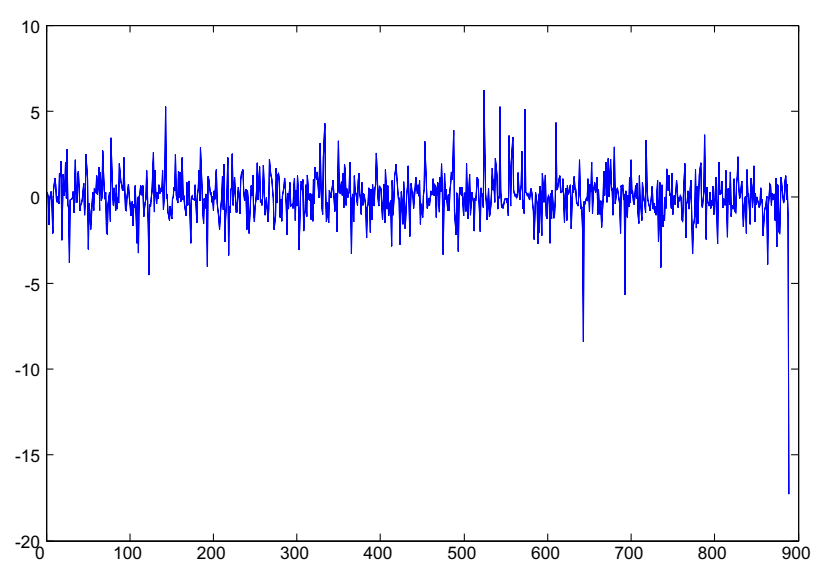

(a) gaussmf-10\%-S1-50

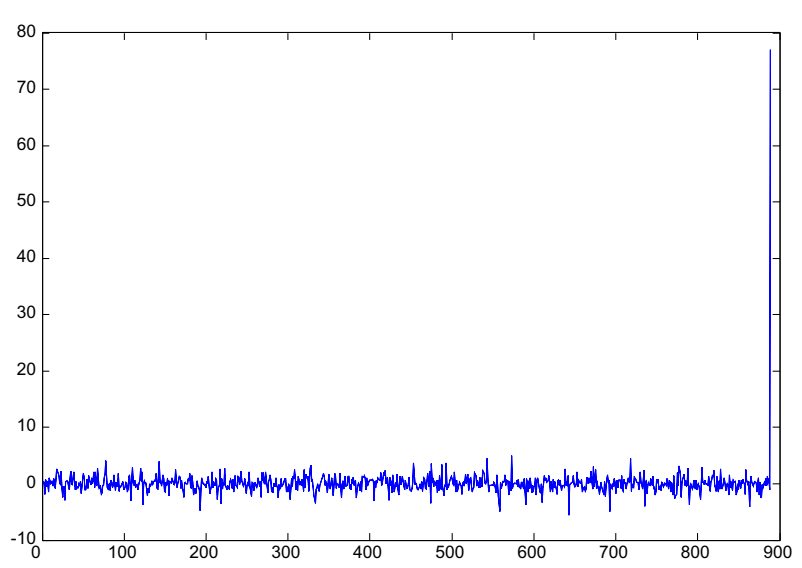

(b) gaussmf-10\%-S4-100

Fig. 19. Damage index variation for damage type $S 1-50$ (a) and damage type $S 4-100$ (b) using MF gaussmf under $10 \%$ noise level.

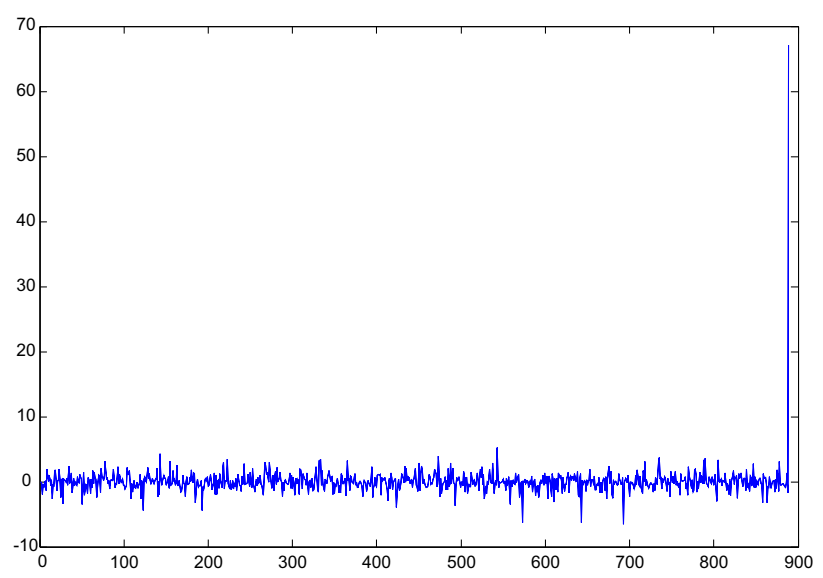

(a) gaussmf-10\%-S5-100

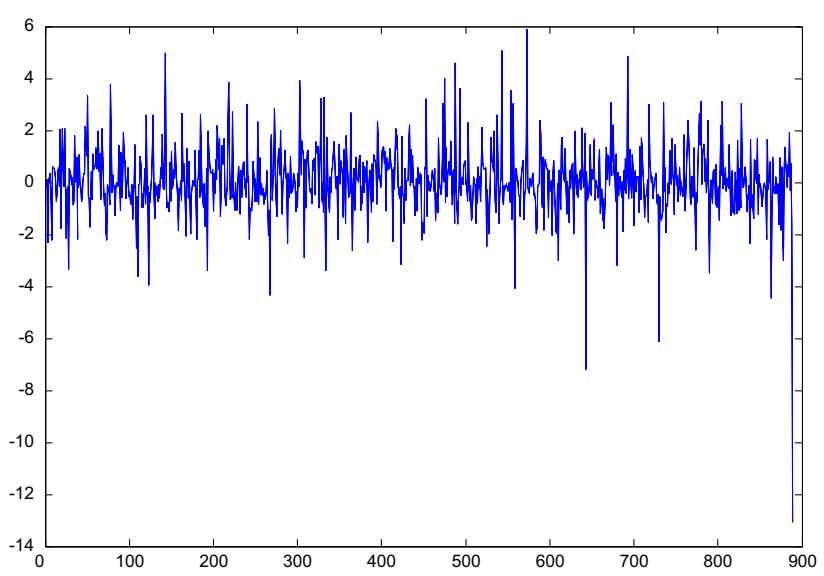

(b) gaussmf-10\%-S8-50

Fig. 20. Damage index variation for damage type S5-100 (a) and damage type S8-50 (b) using MF gaussmf under $10 \%$ noise level.

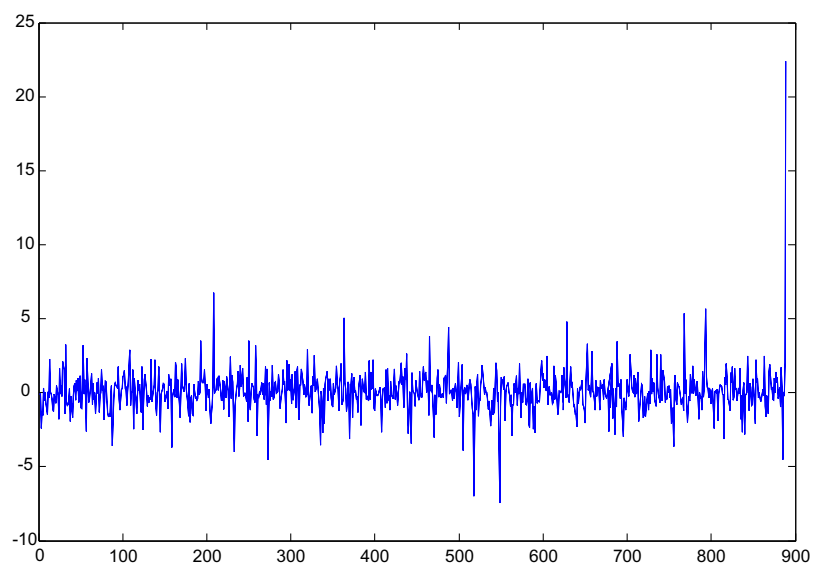

(a) gaussmf-30\%-S1-100

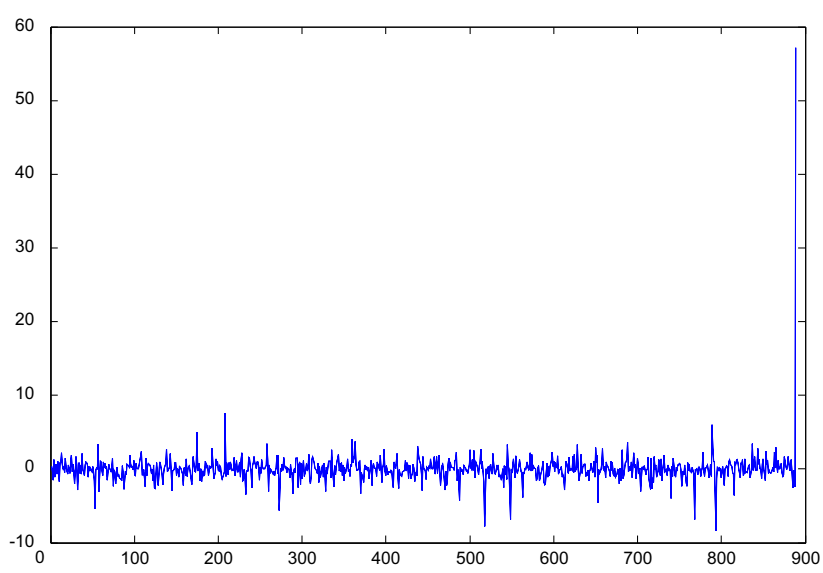

(b) gaussmf-30\%-S4-100

Fig. 21. Damage index variation for damage type $S 1-100$ (a) and damage type S4-100 (b) using MF gaussmf under $30 \%$ noise level.

\subsection{Dynamic identification of unknown damage time and location}

In the process of simulation, three damages (among the 16 kinds of damage) with unknown time and type are applied to the fuselage. In the total $11 \mathrm{~s}$ of the simulation process, the value change of damage index $M$ is monitored in real-time and its variation is shown in Figs. 13-15:

Seen from Figs. 13-15, abnormal value of the damage index occurs at sequence point 889 . Because of the difference between computing sequence of damage index and the actual time, it is 


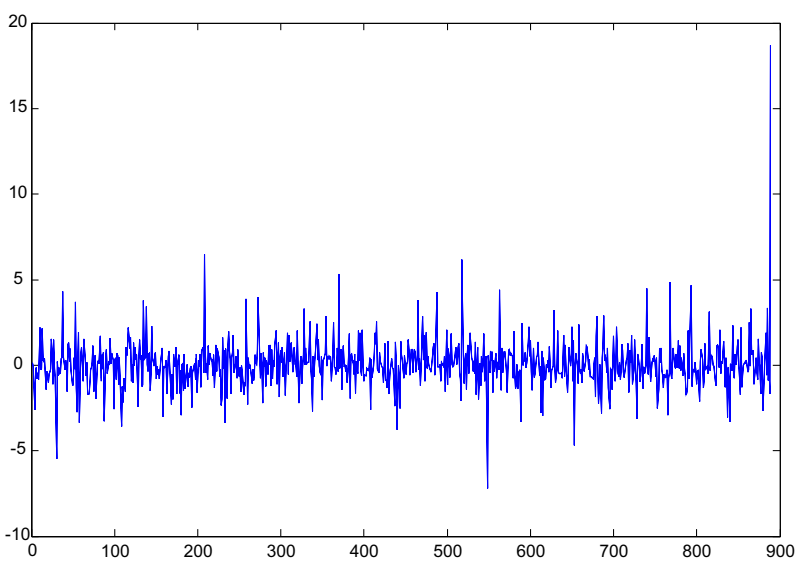

(a) gaussmf-30\%-S5-100

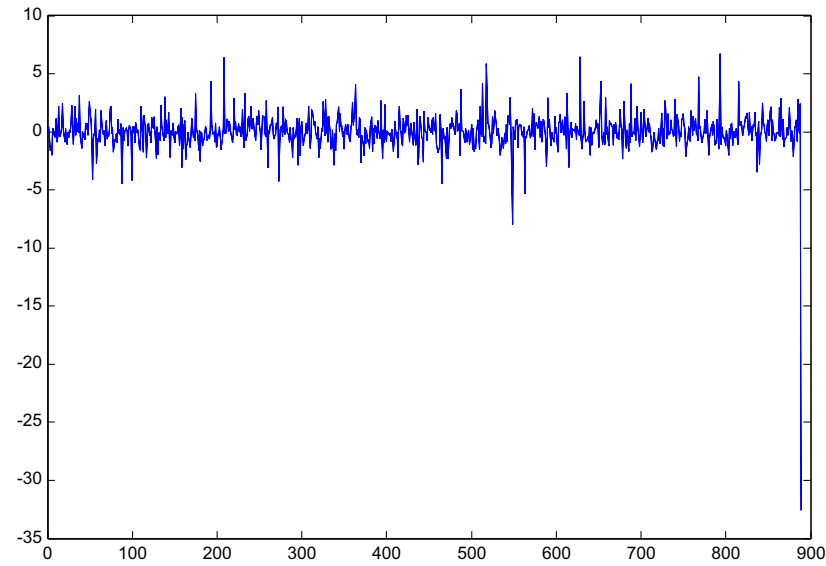

(b) gaussmf-30\%-S8-100

Fig. 22. Damage index variation for damage type S5-100 (a) and damage type S8-100 (b) using MF gaussmf under 30\% noise level.

Table 3

Correspondence between damage index computing sequence and actual time.

\begin{tabular}{llllll}
\hline Index sequence & 1 & 2 & $\ldots$ & 888 & 889 \\
Actual time & $1.13 \mathrm{~s}$ & $1.14 \mathrm{~s}$ & $\ldots$ & $10 \mathrm{~s}$ & $10.01 \mathrm{~s}$ \\
\hline
\end{tabular}

necessary to list the computing sequence corresponding to the actual time, which is shown in Table 3. Based on Table 3, structural damages are identified at $10.01 \mathrm{~s}$, given that all the three damages occur at $10 \mathrm{~s}$. The damages occurring at $10 \mathrm{~s}$ are identified at $10.01 \mathrm{~s}$.

The following is to identify the damage locations. "Location factors" of the three kinds of damage are computed and showed in Fig. 16. From the matching degree in Fig. 16, the results can be seen apparently that unknown damage 1 belongs to the third kind of position; unknown damage 2 the first kind of position; unknown damage 3 the fourth kind of position.

\subsection{Comparisons of related damage identification methods}

Several related damage identification methods are ANFIS-2DWT, CBR, ZOM, and Wavelet-Neuro-Fuzzy, which can be found in references (Bayissa et al., 2008; Escamilla-Ambrosio, Liu, Lieven, \& Ramirez-Cortes, 2011; Kolakowski, 2006; Sunny \& Kapania, 2011).

A structural damage identification approach combining adaptive network-based fuzzy inference system (ANFIS) and 2D wavelet transform (2D WT) technologies (A) is proposed in (EscamillaAmbrosio et al., 2011). Case-based reasoning (CBR) (B) (Kolakowski, 2006) is a soft-computing method utilizing wavelet transformation for signal processing and neural networks for training a

Table 4

Configuration comparisons:

\begin{tabular}{llllll}
\hline Methodology & A & B & C & D & Present paper \\
\hline $\begin{array}{l}\text { Excitation } \\
\text { Model }\end{array}$ & a & b & c & d \\
& Cantilever beam & Cantilever beam & Plate & Membrane & Helicopter Fuselage \\
\hline
\end{tabular}

Table 5

Identification accuracy in example analysis:

\begin{tabular}{|c|c|c|c|c|c|}
\hline \multirow[t]{2}{*}{ Accuracy grade $(\%)$} & \multicolumn{5}{|c|}{ Damage identification accuracy } \\
\hline & A & $\mathrm{B}$ & $\mathrm{C}$ & $\mathrm{D}$ & Present paper \\
\hline 10 & $\sqrt{ }$ & $\sqrt{ }$ & $\sqrt{ }$ & $\sqrt{ }$ & $\sqrt{ }$ \\
\hline 5 & $\sqrt{ }(S N R \geqslant 10)$ & $\sqrt{ }$ & $\sqrt{ }$ & $\sqrt{ }$ & $\sqrt{ }$ \\
\hline 2.5 & & $\sqrt{ }$ & $\sqrt{ }$ & $\sqrt{ }$ & $\sqrt{ }$ \\
\hline 1 & & $\sqrt{ }($ experiment verified $)$ & $\sqrt{ }$ & $\sqrt{ }$ & $\sqrt{ }$ \\
\hline 0.5 & & & $\sqrt{ }(7 \%$ noise $)$ & $\sqrt{ }(-)$ & $\sqrt{ }$ \\
\hline 0.1 & & & & & $\sqrt{ }(30 \%$ noise $)$ \\
\hline 0.05 & & & & & $\sqrt{ }(10 \%$ noise $)$ \\
\hline
\end{tabular}

Table 6

Localization accuracy results:

\begin{tabular}{|c|c|c|c|c|c|}
\hline Methodology & A & B & C & $\mathrm{D}$ & Present paper \\
\hline Locations & 5 & 19 & 1 & 16 & 4 \\
\hline Full size & $90 \mathrm{~cm} \times 2.545 \mathrm{~cm} \times 0.647 \mathrm{~cm}$ & $98 \mathrm{~cm} \times 2 \mathrm{~cm} \times 0.5 \mathrm{~cm}$ & $6 \mathrm{~m} \times 4 \mathrm{~m} \times 0.2 \mathrm{~m}$ & $0.78 \mathrm{~m} \times 0.78 \mathrm{~m} \times 0.001 \mathrm{~m}$ & $1.26 \mathrm{~m} \times 0.25 \mathrm{~m} \times 0.15 \mathrm{~m}$ \\
\hline
\end{tabular}


Table 7

Damage identification effect under different noise level using MF gauss2mf.

\begin{tabular}{clllllllll}
\hline \multirow{2}{*}{ Noise level } & \multicolumn{1}{l}{ Damage location } \\
\cline { 2 - 9 } & \multicolumn{1}{l}{ Brace 1} & \multicolumn{1}{l}{ Brace 4} & & Brace 5 & & Brace 8 \\
\hline \multirow{2}{*}{$5 \%$} & $2.5 \%$ & $\times$ & $4 \%$ & $\sqrt{ }$ & $3 \%$ & $\times$ & $3 \%$ & $\times$ \\
& $15 \%$ & $\times$ & $12 \%$ & $\sqrt{ }$ & $12 \%$ & $\sqrt{ }$ & $12 \%$ & $\times$ \\
& $50 \%$ & $\sqrt{ }$ & $50 \%$ & $\sqrt{ }$ & $50 \%$ & $\sqrt{ }$ & $50 \%$ & $\sqrt{ }$ \\
& $100 \%$ & $\sqrt{ }$ & $100 \%$ & $\sqrt{ }$ & $100 \%$ & $\sqrt{ }$ & $100 \%$ & $\sqrt{ }$ \\
$10 \%$ & $2.5 \%$ & $\times$ & $4 \%$ & $\times$ & $3 \%$ & $\times$ & $3 \%$ & $\times$ \\
& $15 \%$ & $\times$ & $12 \%$ & $\times$ & $12 \%$ & $\times$ & $12 \%$ & $\times$ \\
& $50 \%$ & $\sqrt{ }$ & $50 \%$ & $\times$ & $50 \%$ & $\times$ & $50 \%$ & $\sqrt{ }$ \\
& $100 \%$ & $\sqrt{ }$ & $100 \%$ & $\sqrt{ }$ & $100 \%$ & $\sqrt{ }$ & $100 \%$ & $\sqrt{ }$ \\
& $2.5 \%$ & $\times$ & $4 \%$ & $\times$ & $3 \%$ & $\times$ & $3 \%$ & $\times$ \\
& $15 \%$ & $\times$ & $12 \%$ & $\times$ & $12 \%$ & $\times$ & $12 \%$ & $\times$ \\
& $50 \%$ & $\times$ & $50 \%$ & $\times$ & $50 \%$ & $\times$ & $50 \%$ & $\times$ \\
& $100 \%$ & $\sqrt{ }$ & $100 \%$ & $\sqrt{ }$ & $100 \%$ & $\sqrt{ }$ & $100 \%$ & $\sqrt{ }$ \\
\hline
\end{tabular}

base of damage cases to retrieve a similar relevant case. A new damage identification technique based on the statistical moments of the energy density function of vibration responses in the timescale (or time-frequency) domain $(C)$ is proposed in Bayissa et al. (2008). A damage detection method using a wavelet-based neuro-fuzzy system (D) is proposed in Sunny and Kapania (2011).

The following Tables 4-6 are qualitative and quantitative comparisons among the four methods and the method proposed in this paper. The identification accuracy of different methods is calculated in this paper to make contrasts. It is shown from the tables that damage identification results possess excellent accuracy, meaning that the proposed ANFIS based interval modeling technique is an effective method in aircraft structural health monitoring and damage localization. In Table 4, band-limited $(0-500 \mathrm{~Hz})$ Gauss white noise (a), windowed sine pulse (b), non-stationary random data (c), and sinusoidal signal (d) are used as excitations for structural damage identification.

The identification accuracy is defined as the proportion of damaged part in the full structure size. Damage identification effects depend on the type of excitation, structural complexity, damage type and noise level, among which the type of excitation greatly determines the accuracy of damage identification. Because of the unique characteristic of structural harmonic response, damage identification results are more precise with periodic signal as excitation than random signal as excitation. Many scholars devote themselves to study of structural damage identification under ambient or random excitation, which shows further prospects for engineering applications. This paper explores a structural damage identification method under a more special condition than common ambient excitation conditions. Seen from Table 5, identification accuracy is better when using harmonic response than random response.

The identification accuracy of localization is defined as the ratio of the number of damaged parts with the full structure size. Obviously, the identification effect is better if more locations are determined in smaller structures. Seen from Tables 3 and 4 , the comprehensive identification effect of harmonic response based methods is better than random response based methods.

\subsection{Identification of 16 given types of damage using different MFs}

The parameters that affect the identification results are the MF type, number of fuzzy rules, wavelet type, wavelet threshold value,
Table 9

A certain type of helicopter variable pitch lever design load spectrum (forward flight).

\begin{tabular}{|c|c|c|c|}
\hline Flight speed $i$ & $\begin{array}{l}\text { Time proportion } \\
t_{i} / \%\end{array}$ & $\begin{array}{l}\text { Dynamic load } \\
S_{a} / N\end{array}$ & $\begin{array}{l}\text { Frequency } \\
f_{i} /(c / \mathrm{min})\end{array}$ \\
\hline $100 \mathrm{~km} / \mathrm{h}$ & 9.4 & 1210 & 304 \\
\hline $120 \mathrm{~km} / \mathrm{h}$ & 21.4 & 1430 & 304 \\
\hline $135 \mathrm{~km} / \mathrm{h}$ & 6.8 & 1720 & 304 \\
\hline $150 \mathrm{~km} / \mathrm{h}$ & 9.3 & 2230 & 304 \\
\hline$v_{N E}$ & 0.1 & 3160 & 304 \\
\hline
\end{tabular}

$v_{N E}$ denotes the insurmountable flight speed.

step size and number of sensors. This simulation uses $\mathrm{db}$ wavelet and soft threshold method to rid the signal of its noise. The number of fuzzy rules of ANFIS is set to be 27. Step size of abaqus is $0.01 \mathrm{~s}$ and the number of sensors is 14 . During the simulation process, 16 types of damage are emulated using MF gauss $2 \mathrm{mf}$ to check if the proposed method can identify them. The yes or no results are provided in Table 7.

Damage types, including S1-50, S4-4, S5-12 and S8-50 under 5\% noise level, S1-50, S4-100, S5-100 and S8-50 under 10\% noise level, and S1-100, S4-100, S5-100 and S8-100 under 30\% noise level, are examined using MF gaussmf in contrast with MF gauss2mf. The value change of damage index $M$ is monitored in real-time. Figs. 1722 show the variation of damage index in the total $11 \mathrm{~s}$ of the simulation process under three kinds of noise level.

\subsection{Limitations when the method is applied to engineering}

This paper deals with helicopter structural damage identification problem when frequency and magnitude of harmonic excitation are invariable. Because of the complex operating environment, this method may not be applied to some special flight conditions, such as transient state and maneuvering. A survey of time proportion of different flight conditions in a typical small unmanned helicopter is depicted in Table 8. Flight conditions of large-scale helicopters are more complicated than those in Table 8 , and may be subdivided into more flight states.

For large-scale helicopters, harmonic excitation may vary within the same flight condition, as depicted in Table 9. Dynamic load varies with flight speed whereas the frequency is invariable, which increases the difficulty of helicopter structural damage identification.

This method may not be applied to damage identification in some extreme external environment of helicopter operation. The case study in this paper focuses on a small kind of unmanned helicopter whose flight conditions are relatively simple. The proposed method can be used in flight states where the magnitude and frequency of harmonic excitation are both invariable.

\section{Discussions}

Based on the research of system modeling techniques and uncertainty quantification methods, a novel aircraft structural damage detection and localization method mustering real-time filtering algorithm, adaptive neural fuzzy inference system and interval modeling technique is studied. This paper exploits wavelet algorithm as a digital filtering tool, ANFIS as a structural

Table 8

time scale of one typical small helicopter.

\begin{tabular}{|c|c|c|c|c|c|c|}
\hline Flight conditions & Cruise & Hovering & Rotation & Climb & Transient state & Maneuvering \\
\hline Time proportion/\% & 84 & 5 & 7 & 3.6 & 0.4 & 0.01 \\
\hline
\end{tabular}


modeling tool, and interval modeling technique as a damage feature extractor. This integrated method concentrates on signal processing function to realize vibration-based damage identification and is demonstrated to yield efficient results for damage time determination and damage localization.

Comprehensive damage identification effects of harmonic response based methods are better than those of random response based methods. The effects of damage identification depend on excitation type, structural complexity, damage type and noise level, among which excitation type greatly determines its accuracy. Besides the above factors, the parameters that affect the identification results in this paper also include the MF type, number of fuzzy rules, wavelet type, wavelet threshold value, step size and the number of sensors. Due to the unique characteristic of harmonic response, damage identification results are more precise with periodic signal as excitation than random signal as excitation. Structural damage identification under ambient or random excitation shows further prospects for engineering applications with its adaptivity to common structures. This paper explores a structural damage identification method under a more special condition using harmonic excitation to facilitate rapid identification with a high degree of accuracy.

For wavelet filtering on real-time occasions, this paper uses redundancy sampling frequency algorithm to process sensor output time series. Sampling frequency up to $10 \mathrm{kHz}$ imposes high performance requirements on the data acquisition system. SVD technique is used to construct uncertainty coordinates in the process of information fusion using interval modeling technique. The impact variable in calculation amount and decomposition efficiency is the number of vibration response output sensors.

\section{Conclusions}

In this paper, ANFIS is used for structural modeling. After trained by input-output response data, ANFIS acts as a real structure and outputs structural displacement vector. The structural damage identification method proposed in this paper can realize dynamic identification of unknown damage time and location at $0.01 \mathrm{~s}$ after its occurrence. Thus, we can possibly further realize real-time identification of damage if the computer performance meets the requirements.

This paper deals with helicopter structural damage identification problem when the frequency and magnitude of harmonic excitation are invariable. In extreme situations like transient state and maneuvering, the excitations acting on helicopter fuselage are not harmonic. Thus, structural damage occurring in these flight conditions can not be identified using the method proposed in this paper. The case study in this paper focuses on a small kind of unmanned helicopter whose flight conditions are relatively simple. Flight states with different harmonic excitations acting on the structure may be further divided into sub-states, within which the excitation is stable harmonic excitation. When the helicopter transforms flight conditions or shifts sub-states among the same flight condition, it is necessary to switch identification method corresponding to the frequency and magnitude of harmonic excitation.

The proposed method can realize rapid damage identification at $0.01 \mathrm{~s}$ after its occurrence if the computer performance meets the computing requirements, and this is what makes this paper special. In this paper, all the data during the $11 \mathrm{~s}$ simulation are computed integrally. So it is difficult to judge whether the computer can complete the calculation of data generated in $0.01 \mathrm{~s}$ simulation process within $0.01 \mathrm{~s}$ and to predict which kind of computer can identify at $10.01 \mathrm{~s}$ the damage occurring at $10 \mathrm{~s}$ in real-time.
The identification effect is relatively obvious if simulation analysis is under low noise level, whilst un-conspicuous if under high noise level. The damage status can't be effectively identified at present, and it needs further study. This dynamic identification may also be taken as a kind of real-time approach. Furthermore, as structural damage can be regarded as a dynamic variation of structural parameter, this structural damage identification method may be also exploited as structural parameter identification method. The structural parameter may be updated after structural damage has been identified and located.

\section{Acknowledgment}

This research was supported by the National Natural Sciences Foundation of China (10972019).

\section{References}

Altmann, J., \& Mathew, J. (2001). Multiple band-pass autoregressive demodulation for rolling-element bearing fault diagnosis. Mechanical Systems and Signal Processing, 15, 963-977.

Arzhantsev, S., Li, X., \& Kauffman, J. F. (2011). Rapid limit tests for metal impurities in pharmaceutical materials by X-ray fluorescence spectroscopy using wavelet transform filtering. Analytical Chemistry, 83, 1061-1068.

Bayissa, W. L., Haritos, N., \& Thelandersson, S. (2008). Vibration-based structural damage identification using wavelet transform. Mechanical Systems and Signal Processing, 22, 1194-1215.

Budipriyanto, A., Haddara, M. R., \& Swamidas, A. S. J. (2007). Identification of damage on ship's cross stiffened plate panels using vibration response. Ocean Engineering, 34, 709-716.

Cao, M. S., Cheng, L., Su, Z. Q., \& Xu, H. (2012). A multi-scale pseudo-force model in wavelet domain for identification of damage in structural components. Mechanical Systems and Signal Processing, 28, 638-659.

Catalao, J. P. S., Pousinho, H. M. I., \& Mendes, V. M. F. (2011). Hybrid wavelet-PSOANFIS approach for short-term electricity prices forecasting. IEEE Transactions on Power Systems, 26, 137-144.

Ch, S., \& Mathur, S. (2010). Modeling uncertainty analysis in flow and solute transport model using Adaptive Neuro Fuzzy Inference System and particle swarm optimization. Ksce Journal of Civil Engineering, 14, 941-951.

Chen, D. W., Zhang, J. P., \& Ieee. (2005). Time series prediction based on ensemble ANFIS.

Das, A., Maiti, J., \& Banerjee, R. N. (2010). Process control strategies for a steel making furnace using ANN with bayesian regularization and ANFIS. Expert Systems with Applications, 37, 1075-1085.

Duffey, T. A., Doebling, S. W., Farrar, C. R., Baker, W. E., \& Rhee, W. H. (2001). Vibration-based damage identification in structures exhibiting axial and torsional response. Journal of Vibration and Acoustics-Transactions of the Asme, 123, 84-91.

Escamilla-Ambrosio, P. J., Lieven, N., \& Ieee. (2007). Soft computing feature extraction for health monitoring of rotorcraft structures. In 2007 Ieee international conference on fuzzy systems, Vols 1-4 (pp. 1244-1249).

Escamilla-Ambrosio, P. J., Liu, X., Lieven, N. A. J., \& Ramirez-Cortes, J. M. (2011). ANFIS-2D wavelet transform approach to structural damage identification. In 2011 Annual Meeting of the North American Fuzzy Information Processing Society, NAFIPS'2011, March 18, 2011 - March 20, 2011 (pp. Minist. Commun. Inf. Technol. Azerbaijan; North American Fuzzy Information Processing Society (NAFIPS); IEEE; University of Texas). El Paso, TX, United states: Institute of Electrical and Electronics Engineers Inc.

Gketsis, Z. E., Zervakis, M. E., \& Stavrakakis, G. (2009). Detection and classification of winding faults in windmill generators using Wavelet Transform and ANN Electric Power Systems Research, 79, 1483-1494.

Guo, H., Dong, Z., \& Ma, X. (2009). WANFIS model for monthly runoff forecasting. In Symposium JS.4 at the Joint Convention of the International Association of Hydrological Sciences, IAHS and the International Association of Hydrogeologists, IAH, September 6, 2009 - September 12, 2009 (Vol. 331, pp. 109-113). Hyderabad, India: IAHS Press.

Han, J., Wang, S., Shang, X., \& An, Y. (2009). Application of wavelet analysis on thinfilm wideband monitoring system. In 4th international symposium on advanced optical manufacturing and testing technologies: optical test and measuremen technology and equipment, November 19, 2008 - November 21, 2008. Chengdu, China: SPIE (Vol. 7283, pp. The Chinese Optical Society (COS); CAS, The Institute of Optics and Electronics (IOE); State Key Laboratory of Optical Technology for Microfabrication; Sichuan Optical Society (SOS)).

Jafarizadeh, M. A., Hassannejad, R., Ettefagh, M. M., \& Chitsaz, S. (2008) Asynchronous input gear damage diagnosis using time averaging and wavelet filtering. Mechanical Systems and Signal Processing, 22, 172-201.

Jang, J.-S. R. (1993). ANFIS: Adaptive-network-based fuzzy inference system. IEEE Transactions on Systems, Man and Cybernetics, 23, 665-685.

Jang, J. S. R., \& Sun, C. T. (1993). Functional equivalence between radial basis function networks and fuzzy inference systems. IEEE Transactions on Neural Networks, 4, 156-159. 
Kolakowski, P. (2006). Two approaches to structural damage identification: Model updating versus soft computing. Journal of Intelligent Material Systems and Structures, 17, 63-79.

Lew, J. S. (2011). Structural damage identification with performance-based uncertainty quantification and feedback control. Journal of Intelligent Material Systems and Structures, 22, 1317-1325.

Lew, J.-S., \& Loh, C.-H. (2012). Real-time aircraft structural damage identification with flight condition variations. In A. L. Gyekenyesi, T. Y. Yu, P. J. Shull, A. A. Diaz \& H. F. Wu (Eds.), Nondestructive Characterization for Composite Materials, Aerospace Engineering, Civil Infrastructure, and Homeland Security 2012, Vol. 8347

Lew, J.-S., \& Horta, L. G. (2007). Uncertainty quantification using interval modeling with performance sensitivity. Journal of Sound and Vibration, 308, 330-336.

Li, X. Y., \& Law, S. S. (2008). Damage identification of structures including system uncertainties and measurement noise. AIAA Journal, 46, 263-276.

Manimaran, P., Panigrahi, P. K., \& Parikh, J. C. (2009). Multiresolution analysis of fluctuations in non-stationary time series through discrete wavelets. Physica A: Statistical Mechanics and its Applications, 388, 2306-2314.

Mao, Z., \& Todd, M. (2012). Uncertainty Propagation of Transmissibility-Based Structural Health Monitoring Features. In T. Kundu (Ed.), Health Monitoring of Structural and Biological Systems 2012, Vol. 8348.

Melin, P., Soto, J., Castillo, O., \& Soria, J. (2012). A new approach for time series prediction using ensembles of ANFIS models. Expert Systems with Applications, 39, 3494-3506.

Mitchell, R., Kim, Y., \& El-Korchi, T. (2012). System identification of smart structures using a wavelet neuro-fuzzy model. Smart Materials and Structures, 21, 115009

Mohammed, O A. Khan, A A, El-Tallawy, A M., Nejadpak, A., \& Roberts, M. J. (2012). A wavelet filtering scheme for noise and vibration reduction in highfrequency signal injection-based sensorless control of PMSM at low speed. IEEE Transactions on Energy Conversion, 27, 250-260.

Nair, K. K., \& Kiremidjian, A. S. (2009). Derivation of a damage sensitive feature using the Haar wavelet transform. Journal of Applied Mechanics-Transactions of the Asme, 76.

Najah, A. A., El-Shafie, A., Karim, O. A., \& Jaafar, O. (2012). Water quality prediction model utilizing integrated wavelet-ANFIS model with cross-validation. Neura Computing and Applications, 21, 833-841.

Noh, H. Y., Lignos, D. G., Nair, K. K., \& Kiremidjian, A. S. (2012). Development of fragility functions as a damage classification/prediction method for steel moment-resisting frames using a wavelet-based damage sensitive feature. Earthquake Engineering and Structural Dynamics, 41, 681-696.

Noori, R., Abdoli, M. A., Farokhnia, A., \& Abbasi, M. (2009). Results uncertainty of solid waste generation forecasting by hybrid of wavelet transform-ANFIS and wavelet transform-neural network. Expert Systems with Applications, 36, 9991-9999.

Noori, R., Hoshyaripour, G., Ashrafi, K., \& Araabi, B. N. (2010). Uncertainty analysis of developed ANN and ANFIS models in prediction of carbon monoxide daily concentration. Atmospheric Environment, 44, 476-482.
Peretto, L., Sasdelli, R., \& Tinarelli, R. (2005). Uncertainty propagation in the discrete-time wavelet transform. IEEE Transactions on Instrumentation and Measurement, 54.

Red-Horse, J. R., \& Paez, T. L. (2008). Sandia National Laboratories Validation Workshop: Structural dynamics application. Computer Methods in Applied Mechanics and Engineering, 197, 2578-2584.

Rodger, J. A. (2012). Toward reducing failure risk in an integrated vehicle health maintenance system: A fuzzy multi-sensor data fusion Kalman filter approach for IVHMS. Expert Systems with Applications, 39, 9821-9836.

Saeed, R. A., Galybin, A. N., \& Popov, V. (2013). 3D fluid-structure modelling and vibration analysis for fault diagnosis of Francis turbine using multiple ANN and multiple ANFIS. Mechanical Systems and Signal Processing, 34, 259-276.

Samant, A., \& Adeli, H. (2001). Enhancing neural network traffic incident-detection algorithms using wavelets. Computer-Aided Civil and Infrastructure Engineering, $16,239-245$.

Shim, M. B., \& Suh, M. W. (2002). Crack identification using neuro-fuzzyevolutionary technique. Ksme International Journal, 16, 454-467.

Sunny, M. R., \& Kapania, R. K. (2011). Damage detection in a prestressed membrane using a wavelet-based neuro-fuzzy system. In 52nd AIAA/ASME/ASCE/AHS/ASC structures, structural dynamics and materials conference. Denver, CO, United States: American Institute of Aeronautics and Astronautics Inc.

Takagi, T., \& Sugeno, M. (1985). Fuzzy identification of systems and its applications to modeling and control. IEEE Transactions on Systems Man and Cybernetics SMC$15,116-132$.

Talebizadeh, M., \& Moridnejad, A. (2011). Uncertainty analysis for the forecast of lake level fluctuations using ensembles of ANN and ANFIS models. Expert Systems with Applications, 38, 4126-4135.

Tay, D. B. H. (2004). Balanced-uncertainty optimized wavelet filters with prescribed vanishing moments. Circuits Systems and Signal Processing, 23, 105-121.

Theodoridis, D., Boutalis, Y., \& Christodoulou, M. (2010). Indirect adaptive control of unknown multi variable nonlinear systems with parametric and dynamic uncertainties using a new neuro-fuzzy system description. International Journal of Neural Systems, 20, 129-148.

Wu, X., \& Deng, Z. (2008). Modal parameters identification for flight vehicle based on the continuous wavelet transforms. Journal of Beijing University of Aeronautics and Astronautics, 34, 778-781.

Xu, B., Song, G., \& Masri, S. F. (2012). Damage detection for a frame structure model using vibration displacement measurement. Structural Health Monitoring-An International Journal, 11, 281-292.

Xufei, H., Zhongmin, D., \& Zhitao, S. (2012). An information optimizing scheme for damage detection in aircraft structures. SDHM Structural Durability and Health Monitoring, 8, 193-208.

Zhang, K., Li, H., Duan, Z., \& Law, S. S. (2011). A probabilistic damage identification approach for structures with uncertainties under unknown input. Mechanical Systems and Signal Processing, 25, 1126-1145. 